\title{
Error Analysis in English Writing of Engineering College Students Based on pigai.org.
}

\author{
Sun Rui \\ School of Humanities and Foreign Language \\ Xi'an University of Technology \\ Xi'an, China \\ 675497047@qq.com
}

\begin{abstract}
As an online English compositions revision system, pigai.org is technologically supported by corpus and cloud computing. It has offered convenience to college English-learners as well as English teachers to analyze and correct the mistakes existing in students' English writing. Based on error analysis theory and with the help of the data from pigai.org, this paper generalizes the most common and typical mistakes in 952 compositions of 215 engineering students and finds out that their mistakes mainly fall into four categories: spelling, vocabulary, collocation as well as sentences. Through analysis, we know there are two explanations accounting for this: mother tongue interference and lack of basic knowledge. Accordingly, we put forward some useful suggestions for college English teachers to improve their teaching of English writing.
\end{abstract}

Keywords-English writing; Error analysis; Engineering students; Pigai.org

\section{INTRODUCTION}

Writing, a reflection of students' language organization, communication skill as well as logical thinking, plays a crucial role in students' learning. For college students, the best way to improve their writing is frequent practice with the correct and timely guidance and feedback from their teachers. Nonetheless, due to the vast number of students but limited amount of teachers, students can hardly get feedback from their teachers timely, which leads to little improvement in their English writing. On the other hand, in the traditional way, owing to lack of data support, teachers usually analyze the students' articles according to their subjective judgments, through which they can not figure out the types and frequency of their mistakes. Currently, with the prompt development of modern science, internet technology has been widely used in English teaching. It is the emergence of online writing platform based on corpus and cloud technology that changes the situation of extreme lack of teachers' feedback or delayed feedback from their teachers. Not only can teachers deliver timely feedback to their students, but also they can analyze their mistakes correctly and efficiently with the help of data provided by them among which pigai.org plays a crucial part.

There are many researches focusing on the effect pigai.org have on students' writhing ability. However, most of them only contrast this kind of composition revision with the traditional ones to see whether it has positive effect on students' writing ability. With the help of pigai.org, an online revision system based on corpus and cloud computing, this paper analyzes mistakes made by 215 sophomores of engineering students in four different colleges of Xi'an university of technology according to error analysis in second language acquisition and then puts forward some useful writing suggestions for students of engineering as well as teaching suggestions for college English teachers.

\section{ERROR ANALYSIS THEORY}

First put forward by Corder, [1] error analysis is a theory which focuses on the errors made by second language learners. Its purpose is to find out the strategies learners use in their second language learning process and analyze why they make some mistakes through which we can know the common difficulties they meet. By contrasting second language learner's language used in the talking process (which we call inter language) with native speakers', we find the differences and then find out the rules existing in their mistakes to give them useful advice.

Corder pointed out that there are five steps to follow in error analysis:

- Sample collection

- Error identification (from the perspective of grammar and communication).

- Error classification

- Error explanation (from the perspective of psychology as well as linguistics )

- Error assessment.

This paper aims to provide an error analysis of Chinese engineering students. Johnson [2] argued that errors offer vital clues about the process of second language learning. Zhan huifang [3] found that in her research that misuses of tense and verb form were the most frequent error in Chinese students' writing. Others include those in spelling, use of particular words and phrases and so on. Chou Chun- Hui [4] divided Chinese students' errors into two types and found that roughly half of Chinese-speaking students' errors result from L1 interference. 


\section{GENERAL INTRODUCTION OF PIGAI.ORG AND ITS FUNCTION}

\section{A. Operating Principles}

Pigai.org is an online revision system based on corpus and cloud computing [5]. They have 192 indexes including the relevance, text structure, sentence, collocations, vocabulary and fluency and so on. For each composition task, they will choose more than ten indexes according to their relevance. They compare students' compositions, namely, inter language corpus with the native language corpus inside their system to see to what extent students' expressions are similar to the native ones' and accordingly give them remarks. From this, we can make sure the reliability and validity of pagai.org.

\section{B. Advantages of Pigai.org}

Pigai.org outweighs the traditional way of composition revision in that it is more convenient and timely. Apart from this, it also owns the function of commenting by sentences, plagiarism detection and progress report.

For students' part, there are many functions they can use, such as: self-test composition, test base composition, essay scoring, commenting by sentences, continuing improvement, message service, online service, artificial marking, peer evaluation, corpus dictionary and forum. As for teachers, pigai.org provides the functions of composition assignment, class management, messages from students, composition browse, grades derivation, generality comments, commenting by sentences (including sentence errors, spelling mistakes, Chinglish, phrases of high grades, collocation statistics as well as grammar inspection). There are so many advantages compared with the traditional method of composition revision that both students and teachers can benefit a lot from it.

\section{RESEARCH METHOD AND RESEARCH DESIGN}

\section{A. Research Questions}

In this paper, we want to make clear

- How many kinds of mistakes are there existing in engineering students' compositions?

- Which kind of mistakes they tend to make most.

- How can error analysis contribute to our language teaching?

\section{B. Participant and Data.}

All the participants in this study are engineering students from different colleges in Xi'an University of Technology. In this study, we chose 215 sophomores and asked them to submit one composition each month, at the end of this term, we got 952 effective ones, after which we used the function of generality analysis in pigai.org to collect error sample and mark error types. In this study, we combined quantitative analysis with qualitative analysis to find out the commonest mistakes made by them in a composition. By analyzing the common errors, weak spots, as well as the analysis assessment and test report offered by pigai.net, we can figure out the characteristics and origins of the mistakes students made.

\section{ERROR ANALYSIS OF STUDENTS' COMPOSITION BASED ON PIGAI.ORG}

As table. 1 shows, there are 10123 mistakes in students' 952 compositions which can be briefly divided into four categories: spelling, vocabulary, collocation as well as sentence structures.

Error statistics of students' composition

TABLE I. ERROR STATISTICS OF STUDENTS’ COMPOSITION

\begin{tabular}{|c|c|c|c|c|c|c|c|}
\hline \multicolumn{8}{|c|}{ Mirror Analysis } \\
\hline Level 1 & level 2 & level 3 & \multicolumn{2}{|c|}{ statistic } & ratio & statistic & ratio \\
\hline \multirow{3}{*}{ spelling } & spelling & \multicolumn{3}{|c|}{1182} & $11.68 \%$ & \multirow{3}{*}{5738} & \multirow{3}{*}{$56.68 \%$} \\
\hline & punctuation & \multicolumn{3}{|c|}{3719} & $36.73 \%$ & & \\
\hline & $\begin{array}{c}\text { Case } \\
\text { sensitivity }\end{array}$ & \multicolumn{3}{|c|}{837} & $8.27 \%$ & & \\
\hline \multirow{22}{*}{ vocabulary } & \multirow{7}{*}{$\begin{array}{l}\text { misuse of } \\
\text { property }\end{array}$} & $\begin{array}{c}\mathrm{v} \text { misused } \\
\text { as } \mathrm{n}\end{array}$ & 19 & \multirow{7}{*}{180} & \multirow{7}{*}{$1.78 \%$} & \multirow{22}{*}{1735} & \multirow{22}{*}{$17.14 \%$} \\
\hline & & $\begin{array}{c}\text { adv misused } \\
\text { as adv }\end{array}$ & 11 & & & & \\
\hline & & $\begin{array}{c}\mathrm{n} \text { misused } \\
\text { as } \mathrm{v} \\
\end{array}$ & 11 & & & & \\
\hline & & $\begin{array}{c}\mathrm{n} \text { misused } \\
\text { as adj }\end{array}$ & 39 & & & & \\
\hline & & $\begin{array}{c}\text { adj misused } \\
\text { as adv }\end{array}$ & 17 & & & & \\
\hline & & $\begin{array}{c}\text { adj misused } \\
\text { as n }\end{array}$ & 56 & & & & \\
\hline & & $\begin{array}{l}\text { other kinds } \\
\text { of misuse }\end{array}$ & 27 & & & & \\
\hline & pronoun & \multicolumn{3}{|c|}{29} & $0.29 \%$ & & \\
\hline & \multirow{3}{*}{ verb } & $\begin{array}{c}\text { attribution } \\
\text { of verb }\end{array}$ & 10 & \multirow{3}{*}{250} & \multirow{3}{*}{$2.47 \%$} & & \\
\hline & & form of verb & 93 & & & & \\
\hline & & $\begin{array}{c}\text { non-finite } \\
\text { verb }\end{array}$ & 147 & & & & \\
\hline & adverb & sing & 5 & & $0.05 \%$ & & \\
\hline & \multirow{3}{*}{ article } & $\begin{array}{c}\text { unnecessary } \\
\text { articles }\end{array}$ & 67 & \multirow{3}{*}{330} & \multirow{3}{*}{$3.26 \%$} & & \\
\hline & & $\begin{array}{l}\text { lack of } \\
\text { articles }\end{array}$ & 213 & & & & \\
\hline & & $\begin{array}{c}\text { misuse of } \\
\text { articles }\end{array}$ & 50 & & & & \\
\hline & \multirow{3}{*}{ preposition } & $\begin{array}{l}\text { unnecessary } \\
\text { preposition }\end{array}$ & 39 & \multirow{3}{*}{169} & \multirow{3}{*}{$1.67 \%$} & & \\
\hline & & $\begin{array}{c}\text { lack of } \\
\text { preposition }\end{array}$ & 12 & & & & \\
\hline & & $\begin{array}{c}\text { misuse of } \\
\text { preposition }\end{array}$ & 118 & & & & \\
\hline & conjunction & \multicolumn{3}{|c|}{216} & $2.13 \%$ & & \\
\hline & \multirow{3}{*}{ noun } & singular form & 13 & \multirow{3}{*}{427} & \multirow{3}{*}{$4.22 \%$} & & \\
\hline & & $\begin{array}{c}\text { singular and } \\
\text { plural forms } \\
\text { of nouns }\end{array}$ & 353 & & & & \\
\hline & & $\begin{array}{c}\text { noun } \\
\text { countability }\end{array}$ & 37 & & & & \\
\hline
\end{tabular}




\begin{tabular}{|c|c|c|c|c|c|c|c|}
\hline \multicolumn{8}{|c|}{ Table I. cont } \\
\hline & \multirow{2}{*}{ noun } & $\begin{array}{c}\text { possessive } \\
\text { case of noun }\end{array}$ & 4 & \multirow{2}{*}{427} & \multirow{2}{*}{$4.22 \%$} & & \\
\hline & & $\begin{array}{l}\text { other noun } \\
\text { mistakes }\end{array}$ & 20 & & & & \\
\hline & modal verb & \multicolumn{3}{|c|}{109} & $1.08 \%$ & & \\
\hline & \multirow[t]{2}{*}{ adjective } & $\begin{array}{c}\text { misuse of } \\
\text { comparative } \\
\text { and } \\
\text { superlative } \\
\text { degree }\end{array}$ & 16 & \multirow[t]{2}{*}{20} & \multirow[t]{2}{*}{$0.20 \%$} & & \\
\hline & & $\begin{array}{c}\text { other misuses } \\
\text { of adjectives }\end{array}$ & 4 & & & & \\
\hline \multirow{6}{*}{ collocation } & $\begin{array}{l}\text { verb-object } \\
\text { collocation }\end{array}$ & \multicolumn{3}{|c|}{236} & $2.33 \%$ & \multirow{6}{*}{910} & \multirow{6}{*}{$8.99 \%$} \\
\hline & $\begin{array}{c}\text { fixed } \\
\text { collocation }\end{array}$ & \multicolumn{3}{|c|}{3} & $0.03 \%$ & & \\
\hline & $\begin{array}{l}\text { link verb- } \\
\text { predicative } \\
\text { collocation }\end{array}$ & \multicolumn{3}{|c|}{24} & $0.24 \%$ & & \\
\hline & $\begin{array}{l}\text { adjective- } \\
\text { noun } \\
\text { collocation }\end{array}$ & \multicolumn{3}{|c|}{7} & $0.07 \%$ & & \\
\hline & $\begin{array}{c}\text { subject- } \\
\text { predicate } \\
\text { collocation }\end{array}$ & \multicolumn{3}{|c|}{9} & $0.09 \%$ & & \\
\hline & $\begin{array}{c}\text { other } \\
\text { collocation } \\
\text { mistakes }\end{array}$ & \multicolumn{3}{|c|}{631} & $6.23 \%$ & & \\
\hline \multirow{8}{*}{ sentence } & $\begin{array}{l}\text { lack of } \\
\text { ingredient }\end{array}$ & \multicolumn{3}{|c|}{343} & \multirow{3}{*}{$2.18 \%$} & \multirow{8}{*}{1741} & \multirow{8}{*}{$17.20 \%$} \\
\hline & redundancy & $\begin{array}{c}\text { double } \\
\text { predicate }\end{array}$ & 219 & \multirow{2}{*}{221} & & & \\
\hline & ingredient & $\begin{array}{l}\text { double } \\
\text { subject }\end{array}$ & 2 & & & & \\
\hline & $\begin{array}{l}\text { ingredient } \\
\text { misuse }\end{array}$ & \multicolumn{3}{|c|}{26} & $0.26 \%$ & & \\
\hline & $\begin{array}{l}\text { mistakes in } \\
\text { tense }\end{array}$ & \multicolumn{3}{|c|}{12} & $0.12 \%$ & & \\
\hline & $\begin{array}{c}\text { mistakes in } \\
\text { voice }\end{array}$ & \multicolumn{3}{|c|}{9} & $0.09 \%$ & & \\
\hline & $\begin{array}{c}\text { subject- } \\
\text { predicate } \\
\text { consistency }\end{array}$ & $\begin{array}{l}\text { other subject- } \\
\text { predicate } \\
\text { consistency }\end{array}$ & 664 & 664 & $6.56 \%$ & & \\
\hline & $\begin{array}{c}\text { other } \\
\text { sentence } \\
\text { mistakes }\end{array}$ & \multicolumn{3}{|c|}{466} & $4.60 \%$ & & \\
\hline
\end{tabular}

\section{A. Errors in spelling}

Spelling is the most common error which accounts for $56.68 \%$. Through further analysis of the figure, we learn that words spelling, punctuation and word case rank top 3 among all the error tokens, which totals at 1182,3719,837 and accounts for $11.68 \% .36 .73 \% .8 .27 \%$ respectively of all error types. These kinds of spelling mistakes reflect student' lack of language specification. Some of the examples from our data are as follows:

- Incorrect: In most cases, immersing youself in the wechat would bring forth a set of car accidents.

- Correct: In most cases, immersing yourself in the wechat would bring forth a set of car accidents.

- Incorrect: We shoud_use it to help us.
- Correct: We should use it to help us.

\section{B. Errors in vocabulary}

In the writing samples, the top vocabulary errors are noun errors, up to 427 and accounting for $4.22 \%$, article errors, up to 330 , accounting for $3.26 \%$ and verb errors, up to 250 , accounting for $2.47 \%$. Misuse of singular and plural forms of nouns are the most common mistakes for Chinese engineering students and article errors also take up a big proportion., for verbs, their problem mainly exist in non-finite verbs.

1) Misuse of singular and plural forms.

- Incorrect: Compared with most other cities in the country, Guangzhou people have higher average income and many family become well-to-do family.

- Correct: Compared with most other cities in the country, Guangzhou people have higher average income and many families become well-to-do families.

- Incorrect: We Chat is one of the most popular way.

- Correct: We Chat is one of the most popular ways.

2) Misuse of articles.

- Incorrect: Secondly, this is interesting software.

- Correct: Secondly, this is an interesting software.

- Incorrect: I launched a account on We chat in 2016.

- Correct: I launched an account on We chat in 2016.

3) Misuse of verbs: For the misuses of verbs,Students' problems mainly exist in non-finite verbs.

- Incorrect: In addition to send text messages, We Chat can send voice message.

- Correct: In addition to sending text messages, We Chat can send voice message.

- Incorrect: Let the water flowing day and night.

- Correct: Let the water flow day and night.

\section{Errors in collocations}

1) Collocation errors also take up a considerably large part, which are mainly caused by the negative transfer from their mother tongue. Through the analysis of the data collected, we found other kinds of mistakes ,namely, chinglish, are in a dominant position and verb-object collocation is also an important part which can not be ignored.

- Incorrect: Third, i think my life is limited, so i shouldn't spend a lot of time on studying knowledge.

- Correct: Third, I think my life is limited, so I shouldn't spend a lot of time on gaining knowledge.

- Incorrect: I think that we chat is free is the first, and we chat possess too much function to relax our life and help us to finish some little thing about life. 
- Correct: I think that we chat is free in the first, and we chat possess too much function to relax ourselves and help us to finish some little thing about life.

\section{Errors in sentence}

For sentence errors, the dominant problem lies in subjectpredicate consistency, 664, accounting for $6.56 \%$, then there are other kinds of sentence errors, ingredient missing and ingredient redundancy also account for a large part. The following are some examples from students.

\section{1) Subject-predicate consistency.}

- Incorrect: In spite of this ,some people tend to maintain a standpoint that we chat lead a negative effect on individual, while others convince that a gate to the brilliant world has been open to us.

- Correct: In spite of this, some people tend to maintain a standpoint that we chat leads a negative effect on individual, while others convince that a gate to the brilliant world has been open to us.

- Incorrect: We chat give people benefit about contact.

- Correct: We chat gives people benefit about contact.

2) There are also other kinds of mistakes like this.

- Incorrect: Therefore, Guangzhou residents eat food in restaurant are universal.

- Correct: Therefore, it's universal for Guangzhou residents to eat food in restaurant.

- Incorrect: In my opinion, we chat is very popularity.
- Correct: In my opinion, we chat is very popular.

3) Ingredient missing and ingredient redundancy can not be ignored,too.

- Incorrect: A great number of students fill their washbasin and keep the faucet opening when they washing their face.

- Correct: A great number of students fill their washbasin and keep the faucet opening when they are washing their face.

- Incorrect: At the same time, we chat increasingly popular in people's life currently.

- Correct: At the same time, We Chat has been increasingly popular in people's life currently.

- Incorrect: The most interesting thing is people grab red envelopes in New Year.

- Correct: The most interesting thing is that people grab red envelopes in New Year.

- Incorrect: They like go to dumplings restaurant drink morning tea.

- Correct: They like to go to dumplings restaurant and drink morning tea.

\section{CASE ANALYSIS}

Apart from the general mistakes students make, we also get to know the problem of individual students, through which we can correspondingly give guidance. Take the student, whose number is 3150421132 as an example. Eg: 
1.2 It is a very wasteful phenomenon. [点评] [ $[30$ ]
山[ [推存表达] very : overwhelmingly/exceedingly/extremely/intensely

w [推荐表达] very : more than $\approx$

ש [学习提示] 易混词汇: marvel, miracle, wonder, phenomenon 均含"奇迹”之 意。 $\approx$
2.1 If every one do the same thing,than we may lose more than one pots of water. [点评] [ $[0$ ]

2.2 If this happens every day, the waste water can be a stream. [点评] [ $⿴ 囗 30$ ]

2.3 So it's high time that we should save wafer. [点评] [ $⿴ 囗 0$ 0]

2.4 We can't wait until the water runs out to protect the water. [点评] [ $[30$ 0]

2.5 We should put an end to the phenomenon of wasting water. [点评] [ $[30$ 0]
[句子错误] 请检查do，确认主谓一致。

A. [标点警示] 英文标点符号之后通常须加空格。

ш[推荐表达] we may lose : ...were likely to ... $\approx$

w [拓展辨析] 查看every one和everyone的区别。

w [推荐表达] If : provided that $\approx$

\section{A [冠词警示] the waste water疑似冠词多余。}

$\triangle A$ [标点警示] 该句句首与上一句句尾标点符号之间空格缺失。

ш[学习提示] 易混词汇: waste, garbage, rubbish, litter, debris, junk 均含"废 物，垃圾"之意。

w [推荐表达] If : provided that $\approx$

w [推荐表达] save : set aside $\approx$

$\Psi$ [推荐表达] So : therefore/thus/consequently/accordingly/as a result/for that reason/hence/that's why $\approx$

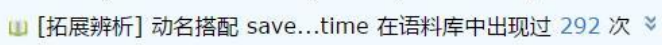

w[拓展辨析] 动名搭配 protect...water 在语料库中出现过 10 次 $~$

w[拓展辨析] 动名搭配 put...end 在语料库中出现过 879 次 $\approx$

Fig. 1. Case study of an individual student from pigai.org

This student has revised four times in all and this is his final revision, from the picture, we can see the main problem still existing in this student's composition is subject-predicate consistency, punctuation and article.
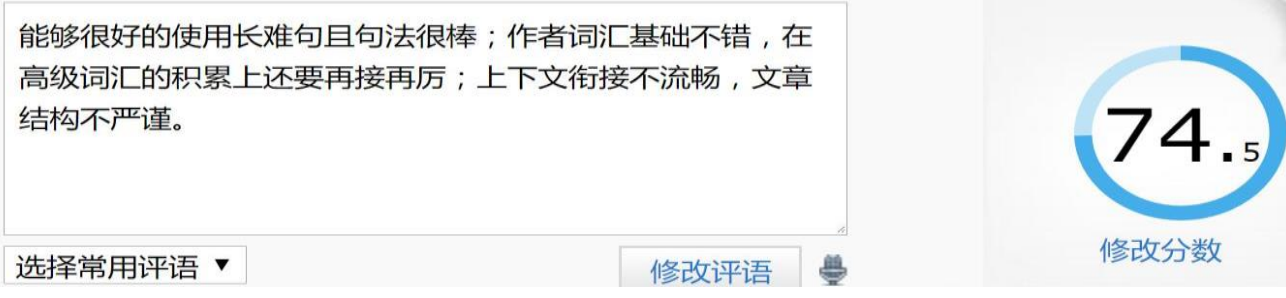

Fig. 2. Remark of an individual student's composition from pigai.org

According to the sentence review function of the pigai.org, it can make a detailed analysis of students' errors in grammar and words, and give the corresponding correction opinions, which has important guiding significance for the improvement of students' writing level. As the picture shows, this student does well in sentence-organization and has a large vocabulary. However, he is not so good at using difficult words and still lacks skill in text organization

\section{EXPLANATION FOR WRITING MISTAKES AND CORRESPONDING SOLUTIONS}

\section{A. Explanations}

1) Mother tongue interference

According to pigai.org, many errors in the writing of engineering students are caused by Chinglish namely, the negative transfer of language. As the psychological basis of error analysis theory, language transfer theory holds that 
language is governed by certain rules and tends to be preconceived [6]. Because the two languages are different in origin, form and grammar, in English writing, students are often affected by Chinese thinking habits and ways of expression, which contributes to distinctive Chinese characteristics in their language usually called Chinglish and this is also a reflection of negative transfer [7]. Owing to limited English input, small amount of information in their brain, lack of accumulation in vocabulary and collocation, most of them lack basic skill of sentence variety, necessary cohesive devices and text layout.

Most of the mistakes mentioned above fall into this category, such as subject-predicate consistency, ingredient missing and ingredient redundancy, Errors in collocations, misuse of singular and plural forms and misuse of articles. In Chinese, We use quantifiers to express the plural concept such as, 堆, 群, 排, 组 and so on while in English, there are no quantifiers, instead, we use singular and plural forms to express their number, affected by Chinese way of thinking, students usually make mistakes in using of singular and plural forms. The similar misuse also occurs in subject-predicate consistency since in Chinese, they don't need to decide which verb form to choose for a subject for there is only one form for a verb.

\section{2) Lack of basic knowledge of language.}

Through the data we can see, spelling mistakes account for $56.68 \%$, which is a reflection of students' weakness in basic knowledge of English. Misuse of punctuation reflects English learners' vague understanding of coherence and cohesion in English sentences, paragraphs as well as texts.

Misuse of word case also occurs as a serious problem. In addition, in word levels, their verb errors, collocation errors and prepositional errors also indicate that their insufficiency of vocabulary and vague understanding of speech conversion, word formation and collocation.

\section{B. Suggestions for Improvement in English Teaching}

Correctly understand the interference of mother tongue and cultivate students' English way of thinking. English, serving as engineering students' second language, will inevitably interfere with their mother tongue. From students' perspective, instead of negatively avoiding this, they should try to take advantages of their mother tongue. We, as language teachers are supposed to give proper guidance to help them improve their English writing. We can help students in the following ways.

Ask them to read original English books to enlarge their vocabulary and avoid word-to-word translation like, red tea (black tea), big snow (heavy snow). Most students nowadays are tied to their smart phones, therefore, as teachers, in order to keep up with them, we have to be familiar with their way of thinking. Apps are so greatly welcomed by students of this generation that instead of trying hard to persuade them to read traditional books, we can recommend some apps for reading for them to make good use of their fragmentation time.

Ask them to have a better understanding of western culture. Some general knowledge of culture in English-speaking countries should be contained in our daily classes, additionally, we can organize some kinds of activities which allow them to experience the original culture of English-speaking countries.

Strengthen the basic skills of language, especially the training of grammar, vocabulary and discourse structure. English writing is based on the mastery of the basic knowledge of the English language. Without a certain language proficiency, it is impossible to write an excellent idiomatic composition.

Grammar is a relatively difficult part for Chinese students. So as teachers, we should create some new ways to teach them grammar. For example, try to design some games in which the grammar rules are included. In learning a word, it will be better for students to try to explain them with English in that it is a very good way to avoid Chinglish and cultivate English way of thinking. Additionally, pronunciation rules are also crucial part through which they can improve their spelling. Besides, for text structure, teachers should encourage students to accumulate some classical sentences patterns.

Students' individual performance can also be reflected through pigai.net. These figures are also valuable for students' improvement. On one hand, we, as language teachers are supposed to motivate students themselves to analyze their assignment with the help of pigai.net frequently so that they can make full use of it. On the other hand, we should give guidance accordingly, especially to those who are under average level.

\section{CONCLUSION}

Based on error analysis, this paper analyses 215 engineering students' composition with the help of pigai.org and finds that their mistakes can be briefly divided into four categories: spelling, vocabulary, collocation as well as sentence structure. Through the analysis of the corresponding reasons, this paper puts forward some useful suggestions. The significance of the study is to help college teachers to know more about their students' way of thinking as well as their common mistakes in English writing and it is of great value for college English teachers to improve their teaching.

\section{REFERENCES}

[1] Corder S.P, “The Significance of Learners'Errors", International Review of Applied Linguistics, 1967(5).

[2] Johnson K, "An introduction to foreign language learning and teaching", Beijing Foreign language Teaching and Research Press,2002.

[3] Huifang Zhan, "Frequent Errors in Chinese EFL Learners", Topic-Based Writings. English Language Teaching, 2015. (In Chinese)

[4] Chun-Hui Chou, "The effectiveness of Chinese NNESTs in Teaching English Syntax", Proceedings of the CATESOL State Conference, 2007. (In Chinese)

[5] Chenghui, Chen, "Marking on Automatic System of Writing", Based on Corpus and Cloud Computing Technologies: Taking pigai.org as an Example, 2013. (In Chinese)

[6] Wang Lei, Xu xiaoyun, "Error analysis in English Writing of Engineering College Students", Based on pigai.org.Journal of Xi'an Petroleum University,pp.95-97,2014. (In Chinese)

[7] Lanling, Liao, "Typical Error analysis in English Writing of College Students ", Based on pigai.org,pp.59-60,2016. (In Chinese) 